\title{
The role of muscle function after anterior cruciate ligament rupture and treatment
}

\author{
Roland Becker ${ }^{1}$. Jon Karlsson ${ }^{2}$
}

Published online: 16 January 2018

(c) European Society of Sports Traumatology, Knee Surgery, Arthroscopy (ESSKA) 2018

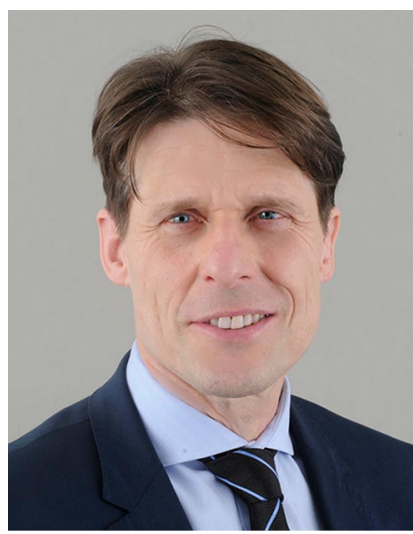

Roland Becker

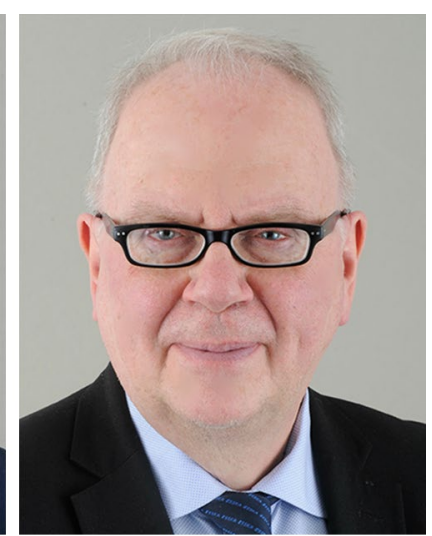

Jon Karlsson
ACL rupture is the fifth most common injury to the musculoskeletal system [3].

The current issue covers three main topics related to ACL ruptures and management, which includes muscle function and knee kinematics, as well as aspects related to surgery and clinical outcome.

The question is whether we pay enough attention to muscle and knee function after an ACL injury. At the ISAKOS meeting in Osaka in 2009, there was a very well-attended session, which focused on single- and double-bundle surgery in ACL reconstruction. The session was followed by a session on muscle function after ACL reconstruction. Regrettably, only a few people participated in this session. This could indicate that orthopaedic surgeons do not appear to

Roland Becker

r.becker@klinikum-brandenburg.de

1 Department of Orthopaedics and Traumatology, Brandenburg Medical School "Theodor Fontane", Hospital Brandenburg, Hochstrasse 26, 14770 Brandenburg/havel, Germany

2 Department of Orthopaedics, Sahlgrenska University Hospital, Sahlgrenska Academy, Gothenburg University, Gothenburg, Sweden pay much attention to knee and muscle function but prefer instead to discuss their surgical techniques, such as singleand double-bundle ACL reconstruction. The last Cochrane Analysis included nine meta-analyses relating to single- versus double-bundle ACL reconstructions [12]. Double-bundle ACL reconstruction appears to produce a better restoration of antero-posterior and rotational knee stability, according to the KT1000 and pivot-shift test, but no difference in functional outcome and the risk of graft failure [12]. The question is whether we can really improve the outcome by improving the surgical technique? The use of the hamstring tendon, quadriceps tendon, or patellar tendon in ACL reconstruction does not appear to have a significant impact on clinical outcome and knee function, although anterior knee pain might occur more frequently when a patellar tendon autograft is used [2, 11, 18]. In the current issue, Runer et al. publish a study which reports no difference in clinical and functional outcome between patients who received either a quadriceps tendon or a hamstring tendon autograft at 2 years of follow-up [17]. Even the tunnel placement in ACL reconstruction remains a topic for discussion. Some studies have shown that tunnel malposition can be regarded as a negative predictive factor for failure in ACL surgery [14]. However, a large analysis of 17,682 revision surgeries after ACL reconstruction showed that the rate of revision was comparable regardless of femoral tunnel drilling using the transtibial or medial portal technique [4].

Another important question is how patients perform many years after ACL injury. There are two very interesting studies in the current issue. Markström et al. have published a study about joint kinematics during a vertical-hop test in patients more than 20 years after ACL rupture; this is the leading paper in the current issue [10]. The study included three groups, one group of patients after ACL reconstruction, a second group after only physiotherapy, while the third group were healthy controls for comparison. The authors used the vertical-hop test to evaluate physical function. Significant changes in movement pattern were reported. Both ACL-injured groups achieved a 
lower hop height on the affected leg, when compared with the contralateral healthy side. However, the hop height did not differ significantly between the ACL-reconstructed group and the healthy group, while it was lower in the physiotherapy group. The interesting message is that there is a persistent and longterm asymmetry in muscle function between the injured and healthy sides. Lower maximum quadriceps contraction and voluntary activation of the injured side in comparison to the uninjured side have been reported by Urbach et al. [19]. The findings are in line with the study by Markström et al. [10]. The voluntary activation of the quadriceps muscle improved significantly bilaterally 13 months after ACL reconstruction but remained lower in comparison to healthy subjects [20]. Changes in quadriceps function have also been reported in other studies [7, 13, 15].

The correlation between muscle function and clinical outcome is well recognised and reduced muscle function may result in an inferior clinical outcome [1]. The study by Perraton et al. published in the current issue evaluated patients 16 months after ACL reconstruction. Patients with poor knee function had lower knee flexion moment angles and ground reaction force [15].

Quadriceps dysfunction remains and appears to affect the performance of athletes. Single-leg landing asymmetries at the time of return to sport will result in poorer knee function even 2 years after ACL reconstruction [8].

Neuromuscular control and quadriceps morphology following ACL rupture were also studied [9]. Two groups, copers and non-copers, were defined. The potential copers were younger, had fewer giving-way episodes, a better Knee Outcome Score, a higher level of activities, and significantly greater quadriceps muscle atrophy. and diminished vastus lateralis muscle control [21].

There is sufficient evidence to indicate that good muscle function is required for successful ACL treatment.

Return to sport has become an important issue when discussing patient performance after ACL treatment. When is the optimal time after ACL treatment to allow athletes to return to sports activity? Different test batteries have been developed to identify the right moment of return, which shows how important muscle function is $[5,6,16]$.

However, many controversies about the management of ACL injuries remain and muscle function and knee kinematics in particular need to be better understood. We maintain that these parameters must be taken into consideration when discussing the optimal treatment for ACL-injured patients.

\section{References}

1. Bodkin S, Goetschius J, Hertel J, Hart J (2017) Relationships of muscle function and subjective knee function in patients after ACL reconstruction. Orthop J Sports Med 5:2325967117719041
2. Cavaignac E, Coulin B, Tscholl P, Nik Mohd Fatmy N, Duthon V, Menetrey J (2017) Is quadriceps tendon autograft a better choice than hamstring autograft for anterior cruciate ligament reconstruction? A comparative study with a mean follow-up of 3.6 years. Am J Sports Med 45:1326-1332

3. Clayton RA, Court-Brown CM (2008) The epidemiology of musculoskeletal tendinous and ligamentous injuries. Injury Netherlands 39:1338-1344

4. Desai N, Andernord D, Sundemo D, Alentorn-Geli E, Musahl V, Fu F, Forssblad M, Samuelsson K (2017) Revision surgery in anterior cruciate ligament reconstruction: a cohort study of 17,682 patients from the Swedish National Knee Ligament Register. Knee Surg Sports Traumatol Arthrosc 25:1542-1554

5. Gokeler A, Welling W, Zaffagnini S, Seil R, Padua D (2017) Development of a test battery to enhance safe return to sports after anterior cruciate ligament reconstruction. Knee Surg Sports Traumatol Arthrosc 25:192-199

6. Hildebrandt C, Müller L, Zisch B, Huber R, Fink C, Raschner C (2015) Functional assessments for decision-making regarding return to sports following ACL reconstruction. Part I: development of a new test battery. Knee Surg Sports Traumatol Arthrosc Germany 23:1273-1281

7. Ithurburn MP, Altenburger AR, Thomas S, Hewett TE, Paterno MV, Schmitt LC (2017) Young athletes after ACL reconstruction with quadriceps strength asymmetry at the time of return-tosport demonstrate decreased knee function 1 year later. Knee Surg Sports Traumatol Arthrosc Germany. https://doi.org/10.1007/ s00167-017-4678-4

8. Ithurburn MP, Paterno MV, Ford KR, Hewett TE, Schmitt LC (2017) Young athletes after anterior cruciate ligament reconstruction with single-leg landing asymmetries at the time of return to sport demonstrate decreased knee function 2 years later. Am J Sports Med 45:2604-2613

9. Macleod TD, Snyder-Mackler L, Buchanan TS (2014) Differences in neuromuscular control and quadriceps morphology between potential copers and noncopers following anterior cruciate ligament injury. J Orthop Sports Phys Ther 44:76-84

10. Markström JL, Tengman E, Häger CK (2017) ACL-reconstructed and ACL-deficient individuals show differentiated trunk, hip, and knee kinematics during vertical hops more than 20 years post-injury. Knee Surg Sports Traumatol Arthrosc. https://doi. org/10.1007/s00167-017-4528-4

11. Mohtadi NG, Chan DS, Dainty KN, Whelan DB (2011) Patellar tendon versus hamstring tendon autograft for anterior cruciate ligament rupture in adults. Cochrane Database Syst Rev CD005960

12. Mundi R, Bhandari M (2016) Cochrane in CORR (®): Doublebundle Versus Single-bundle Reconstruction for Anterior Cruciate Ligament Rupture in Adults (Review). Clin Orthop Relat Res 474:1099-1101

13. Palmieri-Smith RM, Lepley LK (2015) Quadriceps strength asymmetry after anterior cruciate ligament reconstruction alters knee joint biomechanics and functional performance at time of return to activity. Am J Sports Med 43:1662-1669

14. Parkinson B, Robb C, Thomas M, Thompson P, Spalding T (2017) Factors that predict failure in anatomic single-bundle anterior cruciate ligament reconstruction. Am J Sports Med 45:1529-1536

15. Perraton L, Clark R, Crossley K, Pua YH, Whitehead T, Morris H, Telianidis S, Bryant A (2017) Impaired voluntary quadriceps force control following anterior cruciate ligament reconstruction: relationship with knee function. Knee Surg Sports Traumatol Arthrosc 25:1424-1431

16. Rambaud AJM, Semay B, Samozino P, Morin JB, Testa R, Philippot R, Rossi J, Edouard P (2017) Criteria for Return to Sport after Anterior Cruciate Ligament reconstruction with lower reinjury risk (CR'STAL study): protocol for a prospective observational study in France. BMJ Open 7:e015087 
17. Runer A, Wierer G, Herbst E, Hepperger C, Herbort M, Gföller P, Hoser C, Fink C (2017) There is no difference between quadriceps- and hamstring tendon autografts in primary anterior cruciate ligament reconstruction: a 2-year patient-reported outcome study. Knee Surg Sports Traumatol Arthrosc. https://doi.org/10.1007/ s00167-017-4554-2

18. Samuelsen BT, Webster KE, Johnson NR, Hewett TE, Krych AJ (2017) Hamstring autograft versus patellar tendon autograft for ACL reconstruction: is there a difference in graft failure rate? A meta-analysis of 47,613 patients. Clin Orthop Relat Res 475:2459-2468

19. Urbach D, Nebelung W, Röpke M, Becker R, Awiszus F (2000) Bilateral dysfunction of the quadriceps muscle after unilateral cruciate ligament rupture with concomitant injury central activation deficit. Unfallchirurg 103:949-955

20. Urbach D, Nebelung W, Becker R, Awiszus F (2001) Effects of reconstruction of the anterior cruciate ligament on voluntary activation of quadriceps femoris a prospective twitch interpolation study. J Bone Joint Surg Br 83:1104-1110

21. Williams GN, Snyder-Mackler L, Barrance PJ, Buchanan TS (2005) Quadriceps femoris muscle morphology and function after ACL injury: a differential response in copers versus non-copers. $J$ Biomech United States 38:685-693 